\title{
Narrative Review: A Rational Approach to Starting Insulin Therapy
}

\author{
Arshag D. Mooradian, MD; Marla Bernbaum, MD; and Stewart G. Albert, MD
}

Background: The emergence of multiple insulin products has provided new opportunities to achieve diabetes control. However, the number of options has raised concerns about the optimal choices of products.

Purpose: To briefly review the pharmacologic characteristics of currently available insulin products and to suggest an initial insulin regimen based on common blood glucose profiles among patients with diabetes.

Data Sources: Relevant manuscripts were identified through a MEDLINE search (1996 to 25 February 2006) of the English-language literature. The key phrase used was therapeutic use of insulin. The literature search was limited to core clinical journals that have accessible full texts.

Study Selection: Clinical trials and authoritative reviews published between 1996 and February 2006 were selected. A total of 420 manuscripts was reviewed.

Data Extraction: The authors independently reviewed the relevant available literature. This literature, along with the authors' clinical experience, was used to construct practical suggestions.

Data Synthesis: Several new insulin and insulin analogue preparations are now available for clinical use. Used as prandial insulin (for example, insulin lispro, insulin aspart, or insulin glulisine) and basal insulin (for example, insulin glargine or insulin detemir), the analogues simulate physiologic insulin profiles more closely than the older conventional insulins. There is currently no strong rationale favoring glargine, neutral protamine Hagedorn insulin, insulin detemir, or fixed-ratio insulin preparations as the preferred agent for initiating insulin therapy.

Limitations: This was a retrospective review of previously published manuscripts chosen at the authors' discretion.

Conclusions: The advent of recombinant DNA technology made it possible to overcome limitations in the time-action profiles of conventional insulins. Insulin therapy must be individualized. Nevertheless, certain subgroups of patients with diabetes can be differentiated from each other according to the pattern of blood glucose changes during the day. On the basis of the blood glucose profile, the authors suggest an initial insulin regimen that can be used to evaluate individual responsiveness and plan a long-term regimen.

Ann Intern Med. 2006;145:125-134.

www.annals.org
$\mathrm{T}$ ailoring insulin therapy to the blood glucose profiles of patients with diabetes is indisputably a rational strategy. Yet, with the advent of various insulin preparations, the pharmaceutical industry aggressively promotes products to fit the needs of most, if not all, patients with diabetes. Of note, the Diabetes Control and Complications Trial investigators used several different insulin regimens to achieve blood glucose control in patients with type 1 diabetes (1), a population generally more homogeneous in terms of underlying pathophysiologic characteristics than those with type 2 diabetes. Thus, the need for an individualized approach to insulin therapy in patients with diabetes cannot be overemphasized. Nevertheless, certain subgroups of patients with diabetes can be differentiated from each other according to the pattern of blood glucose changes during the day. Therefore, profiling these groups may help practitioners rationally choose a particular insulin regimen. The insulin regimen should subsequently be modified on the basis of the individual's response to therapy. We describe 3 common blood glucose profiles that represent typical patterns among patients with diabetes. On the basis of the blood glucose profile, we suggest an initial insulin regimen that would then be modified according to individual responsiveness. To prime the discussion, we briefly review the pharmacologic characteristics of currently available insulin products.

This review is based on previously published manuscripts that were identified through a MEDLINE search
(1996 to 25 February 2006) of English-language literature. The literature search was limited to core clinical journals that have accessible full texts, and the key phrase used was therapeutic use of insulin. A total of 420 manuscripts were reviewed, but only a select number are quoted to avoid repetitiveness and to adhere to space limitations. Individual references were chosen at the discretion of the authors. All authors independently reviewed the relevant available literature. This literature, along with our clinical experiences, was used to construct practical suggestions.

\section{Pharmacologic Characteristics of Currently AVAILABLE INSULINS}

There are several excellent reviews of the available insulin preparations (2-9). The pharmacokinetic variables of various insulins are summarized in Table 1. Regular human insulin peaks at 2 to 3 hours when given subcutaneously and has a variable duration of action that can range from 6 to 8 hours. Although regular insulin historically has
See also:
Web-Only
CME quiz
Conversion of figures and tables into slides 
Table 1. The Pharmacokinetic Variables of Some of the Most Commonly Used Insulin Preparations*

\begin{tabular}{|c|c|c|c|}
\hline \multirow[t]{2}{*}{ Insulin or Insulin Analogue Preparations } & \multirow{2}{*}{$\begin{array}{l}\text { Name and Location of } \\
\text { Manufacturer }\end{array}$} & \multicolumn{2}{|c|}{ Action Profile, $h$} \\
\hline & & Onset & Peak \\
\hline \multicolumn{4}{|l|}{ Ultra-rapid-acting } \\
\hline Insulin lispro (Humalog) & Eli Lilly, Indianapolis, Indiana & $0.2-0.5$ & $0.5-2$ \\
\hline Insulin aspart (Novolog) & Novo Nordisk, Bagsvaerd, Denmark & $0.2-0.5$ & $0.5-2$ \\
\hline Insulin glulisin (Apidra) & $\begin{array}{l}\text { Aventis Pharmaceuticals, Inc., } \\
\text { Bridgewater, New Jersey }\end{array}$ & $0.2-0.5$ & $0.5-2$ \\
\hline \multicolumn{4}{|l|}{ Short-acting } \\
\hline Regular (human) Humulin R/Novolin R & Eli Lilly, Indianapolis, Indiana & $0.5-1$ & $2-3$ \\
\hline \multicolumn{4}{|l|}{ U-500 (human)t } \\
\hline \multicolumn{4}{|l|}{ Intermediate-acting } \\
\hline NPH (human) Humulin N/Novolin N & Eli Lilly, Indianapolis, Indiana & $1.5-4$ & $4-10$ \\
\hline Insulin detemir (Levemir) & Novo Nordisk, Bagsvaerd, Denmark & $1-3$ & 9-Unknown \\
\hline \multicolumn{4}{|l|}{ Long-acting } \\
\hline Insulin glargine (Lantus) & $\begin{array}{l}\text { Aventis Pharmaceuticals, Inc., } \\
\text { Bridgewater, New Jersey }\end{array}$ & $1-3$ & No peak \\
\hline \multicolumn{4}{|l|}{ Mixtures (human) $\neq$} \\
\hline 70/30 Humulin/Novolin (70\% NPH, 30\% regular) & Eli Lilly, Indianapolis, Indiana & $0.5-1$ & $3-12$ \\
\hline $50 / 50$ Humulin ( $50 \% \mathrm{NPH}, 50 \%$ regular) & Eli Lilly, Indianapolis, Indiana & $0.5-1$ & $2-12$ \\
\hline \multicolumn{4}{|l|}{ Mixtures (insulin analogues) } \\
\hline 75/25 Humalog (75\% NPL, $25 \%$ lispro) & Eli Lilly, Indianapolis, Indiana & $0.2-0.5$ & $1-4$ \\
\hline $50 / 50$ Humalog (50\% NPL, $50 \%$ lispro ) & Eli Lilly, Indianapolis, Indiana & $0.2-0.5$ & $1-4$ \\
\hline $\begin{array}{l}70 / 30 \text { Novolog Neutral (70\% protamine aspart, } \\
30 \% \text { aspart) }\end{array}$ & Novo Nordisk, Bagsvaerd, Denmark & $0.2-0.5$ & $1-4$ \\
\hline
\end{tabular}

${ }^{*} \mathrm{NPH}=$ neutral protamine Hagedorn; NPL $=$ neutral protamine lispro.

† All preparations available in the United States are concentrated as U-100 $(100 \mathrm{U} / \mathrm{mL})$.

₹ Mixtures with different proportions of NPH and regular insulin are also available in Europe.

been used to target postprandial hyperglycemia, its timeaction profile is far from the physiologic pancreatic postprandial insulin burst. The advent of recombinant DNA technology has made it possible to improve the time-action profile of regular insulin. The structural modifications of these novel analogues are shown in Figure 1. Currently, there are 3 rapid-acting insulin analogues with similar pharmacokinetic profiles that are more suitable for targeting postprandial hyperglycemia: insulin lispro (Humalog, Eli Lilly, Indianapolis, Indiana), insulin aspart (Novolog, Novo Nordisk, Bagsvaerd, Denmark), and insulin glulisine (Apidra, Aventis Pharmaceuticals, Inc., Bridgewater, New Jersey). These insulin analogues are rapidly absorbed $(<30$ minutes) after subcutaneous injection, peak at 1 hour, and have a shorter duration of action ( 3 to 4 hours) than regular insulin (10-12). Furthermore, the intraindividual variability in time to maximum serum insulin concentration is clinically significantly less for rapid-acting insulin analogues than for regular human insulin preparations $(10-13)$.

The rapid-acting insulin analogues should be injected 5 to 15 minutes before a meal. However, in infants or in older adults with dementia who both have unpredictable eating patterns, rapid-acting analogues can be administered after the meal without excessive deterioration of glycemic control $(14,15)$.
Intermediate-acting insulins, such as neutral protamine Hagedorn (NPH) or lente insulin, have a delayed onset of action ranging between 2 to 4 hours, can take approximately 6 to 7 hours to reach peak concentration, and can last up to 20 hours. This leads to a distinct peakand-trough effect, and therefore, when used as basal insulin, 2 or more injections are often required each day to minimize the daily excursions of insulin levels. Recently, production of lente and ultralente insulins was discontinued because of their decreasing market shares.

Long-acting insulin glargine has an onset of action of approximately 2 hours, reaches a plateau of biological action at 4 to 6 hours, and lasts up to 24 hours $(9,16)$. The timing of insulin glargine administration should be individualized, although it is minimally important as long as the insulin is administered at the same time every day (17).

Compared with bedtime NPH insulin, insulin glargine is associated with less nocturnal hypoglycemia in patients with type 2 diabetes $(28.8 \%$ vs. $12.6 \%$, respectively; $P=0.011)(18,19)$. If nocturnal hypoglycemia occurs after evening or bedtime administration of insulin glargine, the timing of the injection should be changed to the morning.

Insulin detemir is another long-acting basal insulin analogue that is soluble at neutral $\mathrm{pH}$. It has a unique mechanism of action (20-23). After subcutaneous injection, in- 
sulin detemir binds to albumin through its fatty acid chain. At steady state, the variability in the concentration of free, unbound insulin is then greatly reduced, resulting in stable plasma glucose levels $(20-23)$. The duration of action of insulin detemir is approximately 20 hours at a dose of 0.4 $\mathrm{U} / \mathrm{kg}$ of body weight (22). Insulin detemir is therefore administered twice daily in most patients. As with insulin glargine, insulin detemir has a more stable, less variable pharmacokinetic profile than does NPH.

There are 2 premixed conventional insulins: Humulin 50/50 (Eli Lilly, Indianapolis, Indiana), which consists of $50 \% \mathrm{NPH}$ and 50\% regular insulin, and Humulin 70/30 (Eli Lilly) or Novolin (70/30) (Novo Nordisk, Bagsvaerd, Denmark), which consists of 70\% NPH and 30\% regular insulin. In some countries, additional premixed insulins with different proportions of NPH and regular insulin are available. Rapid-acting insulin analogues are also available in premixed preparations with rapid and intermediate insulin activity (Table 1 ). Self-mixing of insulin combinations in 1 syringe may be difficult for some patients and may result in errors of dosing. Fixed-mixed combinations may simplify the insulin regimen and reduce the number of daily injections.

Three types of fixed-ratio insulin analogue mixes are currently available: Humalog mix 75/25 (Eli Lilly), a 75\% insulin lispro protamine suspension with $25 \%$ insulin lispro; Humalog mix 50/50 (Eli Lilly), a 50\% insulin lispro protamine suspension with $50 \%$ insulin lispro; and Novo- $\log \operatorname{mix} 70 / 30$ (Novo Nordisk), a 70\% insulin aspart protamine suspension with 30\% insulin aspart.

Conventional premixed human insulins have an onset of action of approximately 0.5 to 2 hours, usually plateau at 3 to 6 hours, and last up to 24 hours. Insulin analogue mixes have an onset of action of approximately 15 minutes, reach a peak biological action at 1 to 4 hours, and last up to 24 hours (24). Of note, there is clinically significant interindividual variability in the pharmacokinetics of insulin, and the profile often depends on the dose that is administered. However, the pharmacokinetics of insulin analogues have less intraindividual variability than human insulin.

The availability of insulin analogues enhances flexibility and convenience for insulin-treated patients, and this increased flexibility in insulin timing is associated with an improvement in quality-of-life measures (25). The increasing variety of insulin preparations allows more opportunities to achieve control. The downside is the increased challenge facing health care providers in making the right choices in insulin therapy.

\section{Choosing the Insulin Preparation}

Protocols for insulin use depend on patient location, comorbid conditions, and available resources. All patients with type 1 diabetes require insulin therapy, whereas the indications for insulin therapy in patients with type 2 dia-

Figure 1. The structural modifications of insulin found in insulin analogues.

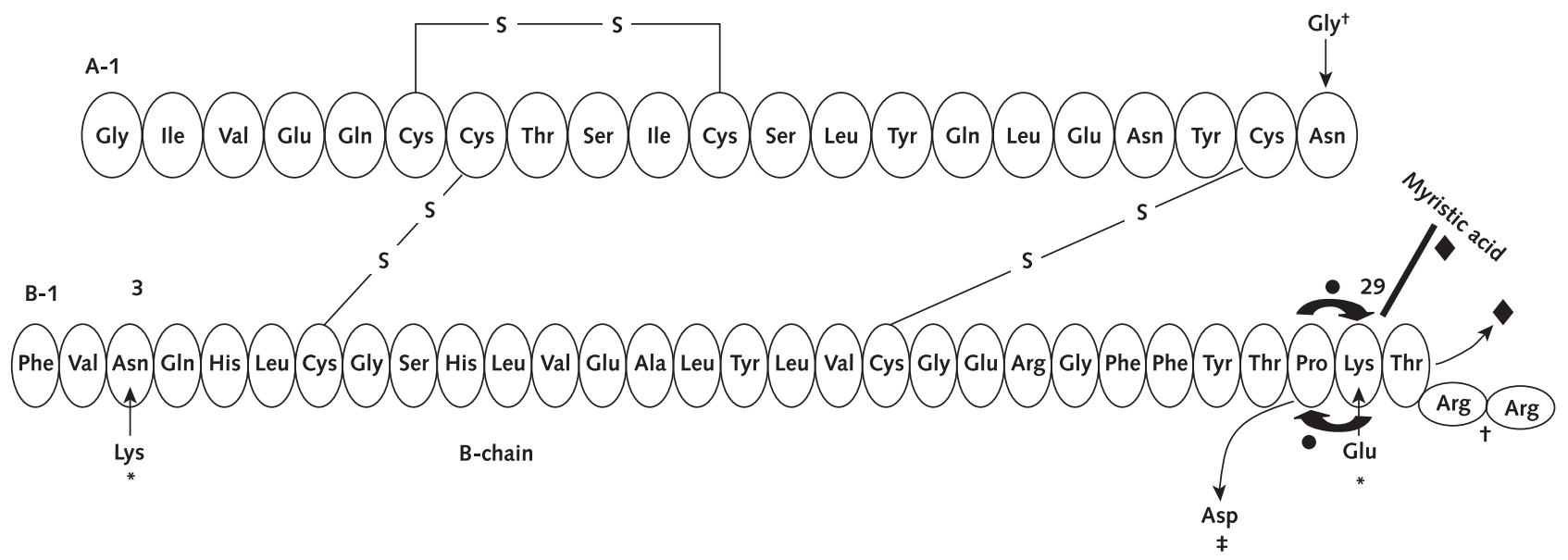

- = Insulin lispro differs from human insulin by the substitution of proline with lysine at position 28 and the substitution of lysine with proline at position 29 of the insulin $\beta$ chain.

$¥=$ Insulin aspart is designed with the single replacement of the amino acid proline by aspartic acid at position 28 of the human insulin $\beta$ chain.

* = Insulin glulisine is designed with the substitution of the amino acid lysine with asparagine at position 3 of the human insulin $\beta$ chain and by substitution of the amino acid lysine at position 29 with glutamine.

$\dagger=$ Insulin glargine differs from human insulin in that the amino acid asparagine at position A21 is replaced by glycine and 2 arginines are added to the C-terminus of the $\beta$ chain.

$\downarrow=$ Insulin detemir is designed to bind albumin in plasma after absorption. Threonine is omitted from position 30 of the insulin $\beta$ chain and replaced by myristic acid, a C14 fatty acid chain.

Figure reprinted with permission from reference 2: Oiknine R, Bernbaum M, Mooradian AD. A critical appraisal of the role of insulin analogues in the management of diabetes mellitus. Drugs. 2005;65:325-40. [PMID: 15669878] 
Table 2. Common Profiles of Blood Glucose Levels in Patients with Diabetes Who Are Not Candidates for or Who Have Had Treatment Failure with Oral Antidiabetic Agents*

\begin{tabular}{|c|c|c|}
\hline Blood Glucose Profile & Patient Subgroups & Recommended Initial Insulin \\
\hline \multirow{12}{*}{$\begin{array}{l}\text { Fasting and postprandial } \\
\text { hyperglycemia }\end{array}$} & Patients in the intensive care unit & Regular human insulin intravenous infusion; discontinue OAD therapy \\
\hline & \multirow[t]{3}{*}{ Type 1 diabetes } & First choice: glargine and premeal rapid-acting insulint \\
\hline & & $\begin{array}{l}\text { Second choice: insulin NPH or detemir twice per day and premeal } \\
\text { rapid-acting insulint }\end{array}$ \\
\hline & & $\begin{array}{l}\text { Third choice: insulin NPH twice per day or at night and premeal regular } \\
\text { human insulin } 3 \text { times per day. Do not miss mealst }\end{array}$ \\
\hline & \multirow[t]{4}{*}{ Type 2 diabetes with significant insulinopenia } & First choice: NPH twice per day†‡ \\
\hline & & Second choice: Glargine nighttime or detemir twice per day \\
\hline & & Continue OAD and add premeal insulin as neededt \\
\hline & & Alternative choice: premixed insulin before breakfast and suppert \\
\hline & Glucocorticoid therapy twice per day & $\begin{array}{l}\text { Same as for patients with type } 2 \text { diabetes with significant } \\
\text { insulinopenia§ }\end{array}$ \\
\hline & \multirow[t]{2}{*}{ Older frail persons with type 2 diabetes } & First choice: glargine in the morning§ \\
\hline & & Second choice: NPH or detemir twice per day§ \\
\hline & Gestational diabetes & NPH twice per day and premealt regular human insulin \\
\hline \multirow{3}{*}{$\begin{array}{l}\text { Fasting hyperglycemia and } \\
\text { daytime euglycemia }\end{array}$} & \multirow{3}{*}{$\begin{array}{l}\text { Type } 2 \text { diabetes with large supper and bedtime } \\
\text { snacking, active during the daytime, and limited } \\
\text { bioactivity of insulin secretagogues }\end{array}$} & First choice: insulin NPH or insulin detemir at night† \\
\hline & & $\begin{array}{l}\text { Second choice: short-acting insulin at supper if bedtime blood glucose } \\
\text { level is }>7.7 \mathrm{mmol} / \mathrm{L}(>140 \mathrm{mg} / \mathrm{dL}) \S\end{array}$ \\
\hline & & Continue OAD \\
\hline \multirow{4}{*}{$\begin{array}{l}\text { Postprandial hyperglycemia } \\
\text { and fasting euglycemia }\end{array}$} & \multirow{2}{*}{$\begin{array}{l}\text { Type } 2 \text { diabetes with partial failure of OADs, } \\
\text { end-stage liver disease, or end-stage kidney } \\
\text { disease }\end{array}$} & First choice: NPH or detemir insulin in the morning§ \\
\hline & & Second choice: rapid- or short-acting insulin before 1 or more meals§ \\
\hline & Morning glucocorticoid therapy & $\begin{array}{l}\text { NPH or detemir insulin in the morning and rapid- or short-acting insulin } \\
\text { before meals as needed§ }\end{array}$ \\
\hline & Gestational diabetes & $\mathrm{NPH}$ in the morning and premeal regular human insulin as needed $t$ \\
\hline
\end{tabular}

${ }^{*} \mathrm{NPH}=$ neutral protamine Hagedorn; $\mathrm{OAD}=$ oral antiglycemic drug.

+ The efficacy and safety of the insulin regimen selected has been shown in clinical trials (that is, evidence-based recommendation).

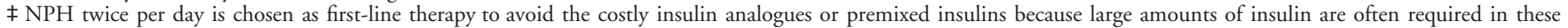
patients.

$\S$ Expert opinion.

betes include symptomatic hyperglycemia, failure of oral therapy, pregnancy, acute illness necessitating surgery, acute myocardial infarction or cardiovascular surgery, and admission to an intensive care unit. The proper timing of initiation of insulin therapy, when oral agents are not achieving glycemic goals, depends on such variables as severity of hyperglycemia, economic and psychosocial circumstances of the patient, and his or her preferences. In general, insulin is the most cost-effective intervention in patients who have not obtained their glycemic goal despite taking 2 or more oral agents. Patients with diabetes present with a wide spectrum of blood glucose profiles (Table 2).

\section{Profile 1: Fasting and Daytime Postprandial Hyperglycemia ("Round-the-Clock" Hyperglycemia)}

Profile 1 is common in diabetic patients referred to endocrinology practices. These patients have either type 1 diabetes or type 2 diabetes with significant insulinopenia.

The pathophysiologic characteristics of fasting and postprandial hyperglycemia are complex. The fasting blood glucose level is determined predominantly by the regulation of glucose production by the liver $(26-28)$. The level of insulin in the portal circulation suppresses glycogenolysis and gluconeogenesis. Peripheral insulin decreases glucagon secretion and limits lipolysis with subsequent free fatty acid-induced gluconeogenesis $(29,30)$.

Many factors affect postprandial hyperglycemia (31,
32 ), including the amount of carbohydrate ingestion and rate of absorption (33), the loss of early-phase insulin secretion (34), the rate of glucagon secretion (33), the effect of these hormones on glucose uptake in muscle, and suppression of hepatic glucose production (35).

\section{Patients with Type 1 Diabetes}

For patients in intensive care units, the most appropriate management would be the initiation of an intravenous insulin drip with frequent monitoring and titration of the insulin dose $(36,37)$. Many insulin infusion protocols are currently used. The protocol for the insulin drip we have been using is shown in Figure 2. The intravenous insulin drip should use human regular insulin only because there is no advantage of any currently available insulin analogues in this setting.

Patients with new-onset type 1 diabetes are best treated with a combination of background basal insulin and short-acting insulin taken before meals. The background insulin is preferably initiated as insulin glargine, although NPH insulin or insulin detemir given twice per day are alternative approaches. The rapid-acting insulin analogues are preferred for prandial coverage. Subsequent adjustments in insulin protocol or the decision to initiate insulin pump therapy will depend on individual responses and preferences. 
Many patients with type 1 diabetes may benefit from continuous subcutaneous insulin infusion therapy delivered by commercially available insulin pumps. This approach provides increased flexibility in dosing and may improve quality of life in some patients. A meta-analysis of the studies evaluating the efficacy and safety of insulin pump therapy has found a modest advantage of this approach compared with multiple-dose insulin injection protocols $(38,39)$. Currently, initiation of insulin pump therapy should be individualized, considering the patient's preferences, lifestyle, and self-care capabilities. The discus- sion of the choice of devices used and the implementation protocols of therapy are beyond the scope of this paper.

\section{Patients with Type 2 Diabetes}

Patients with type 2 diabetes and round-the-clock hyperglycemia have significant insulinopenia with or without severe insulin resistance. Examples of such patients include those with latent adult-onset type 1 diabetes, those who are obese and have severe insulin resistance, those who are older and frail (often women with brittle diabetes) (40), and those receiving high doses of glucocorticoid therapy

Figure 2. A suggested protocol for insulin infusion.

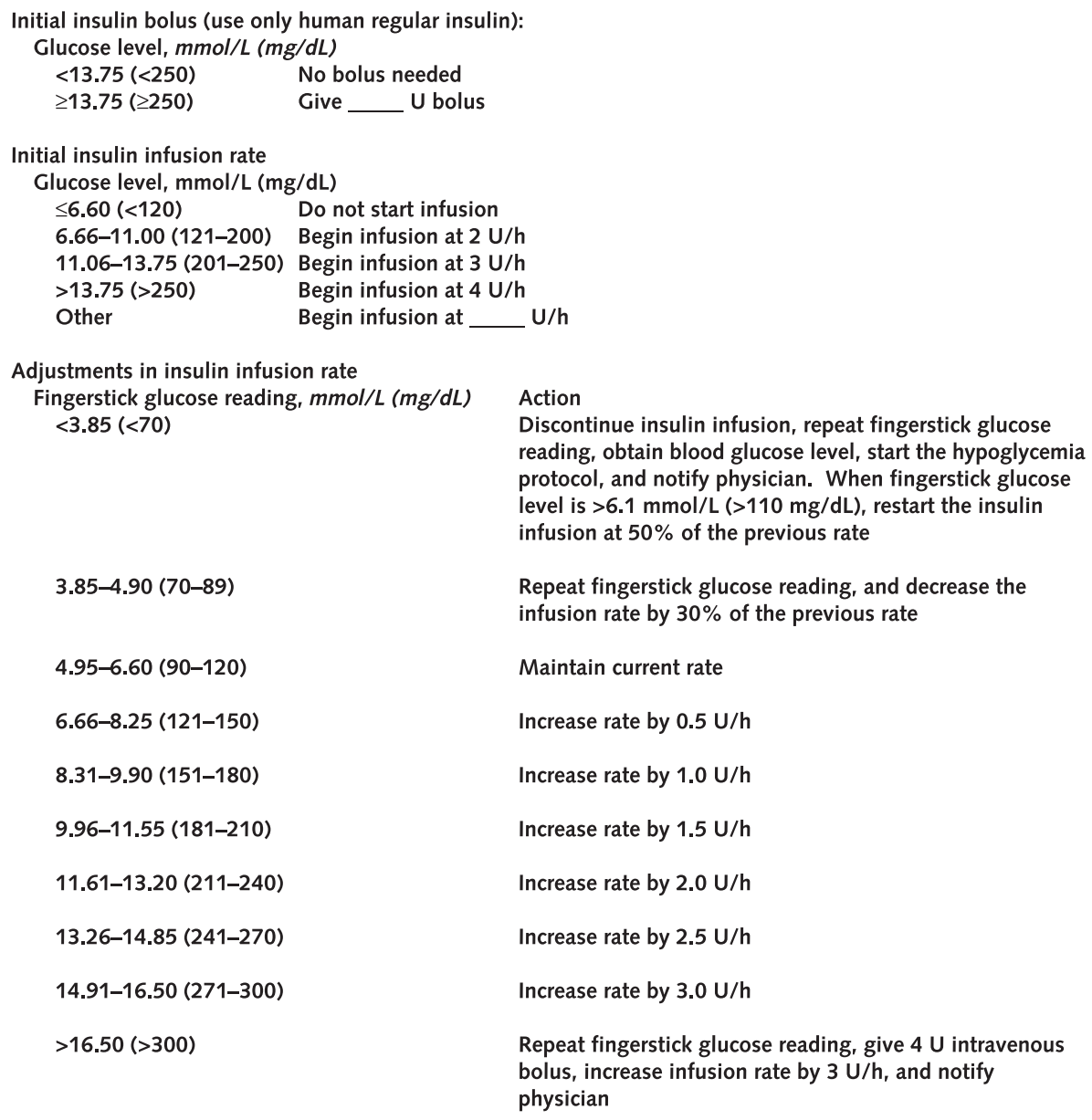

Decrease the infusion rate: If the fingerstick glucose level decreases by more than $50 \%$ in 1 hour, decrease the infusion rate by $50 \%$ and notify the physician, that is, new rate $=0.5$ (previous rate)

\begin{abstract}
Do not increase the infusion rate: 1) If fingerstick glucose level is within target range of $4.95-6.60 \mathrm{mmol} / \mathrm{L}$ $(90-120 \mathrm{mg} / \mathrm{dL}), 2)$ if fingerstick glucose level has decreased by more than $1.10 \mathrm{mmol} / \mathrm{L}(>20 \mathrm{mg} / \mathrm{dL}$ ) from previous 1- $\mathrm{h}$ glucose level of less than $8.80 \mathrm{mmol} / \mathrm{L}(<160 \mathrm{mg} / \mathrm{dL})$, or 3 ) if fingerstick glucose level has decreased by more than $1.65 \mathrm{mmol} / \mathrm{L}(>30 \mathrm{mg} / \mathrm{dL}$ ) from previous 1-h glucose level of $8.86-11.00 \mathrm{mmol} / \mathrm{L}$ (161-200 $\mathrm{mg} / \mathrm{dL})$, or 4) if fingerstick glucose level has decreased by more than $2.75 \mathrm{mmol} / \mathrm{L}(>50 \mathrm{mg} / \mathrm{dL}) \mathrm{from}$ previous 1-h glucose level of $>11.00 \mathrm{mmol} / \mathrm{L}(>200 \mathrm{mg} / \mathrm{dL})$.
\end{abstract}

Adapted from the protocol that is used at the Saint Louis University Hospital with some modifications. Glucose is obtained with fingerstick unless otherwise specified. The protocol is based on expert opinion and has not yet been validated prospectively. 
Table 3. Titration Schedule for Basal and Preprandial Insulin

\begin{tabular}{|c|c|c|c|}
\hline $\begin{array}{l}\text { Fasting Blood Glucose } \\
\text { Levels for } 3 \text { Consecutive } \\
\text { Days, } m m o l / L(m g / d L)\end{array}$ & $\begin{array}{l}\text { Adjustment of } \\
\text { Basal Insulin } \\
\text { Dose, } U^{*}\end{array}$ & $\begin{array}{l}\text { Preprandial or Bedtime } \\
\text { Glucose Levels for } 3 \\
\text { Consecutive Days, } \\
m m o l / L(m g / d L)\end{array}$ & $\begin{array}{l}\text { Adjustment of } \\
\text { Rapid-Acting } \\
\text { Insulin Dose, } \\
\text { U/injectiont }\end{array}$ \\
\hline$\geq 9.90(>180)$ & 8 & $>9.90(180)$ & 3 \\
\hline 7.70 to 8.75 ( 140 to 159$)$ & 4 & 7.70 to 8.75 ( 140 to 159$)$ & 2 \\
\hline 6.60 to 7.65 (120 to 139$)$ & 2 & 6.60 to 7.65 (120 to 139$)$ & 1 \\
\hline 5.50 to 6.55 (100 to 119$)$ & 1 & 5.50 to 6.55 (100 to 119$)$ & Maintain dose \\
\hline$<3.30(<60) \ddagger$ & -4 & $<3.30(<60)$ & -4 \\
\hline
\end{tabular}

* The efficacy and safety of the insulin regimen selected has been shown in clinical trials (that is, evidence-based recommendation).

† Expert opinion. If the patient has an elevated blood glucose level at lunchtime, the breakfast rapid-acting insulin dose should be adjusted; if the patient has an elevated preprandial blood glucose level at dinner time, the lunchtime rapid-acting insulin dose should be adjusted; if the patient has an elevated bedtime glucose level, the dinnertime rapid-acting insulin dose should be adjusted. Adapted from references 19, 36, 37, and 41 .

\# Reduction in insulin dose of 4 or more units as appropriate.

twice per day for autoimmune disease or for antirejection therapy after organ transplantation (Table 2).

In patients with type 2 diabetes, intermediate- or longacting insulin may be added to existing oral antiglycemic agents to control fasting blood glucose levels. Adjustment of the insulin dose is first based on the fasting blood glucose level. For example, the initial dose of insulin glargine would depend on the patient's weight. In general, a starting dose of 10 to $15 \mathrm{U}$ given at bedtime is appropriate. The dose is subsequently increased by 1 to $2 \mathrm{U}$ for every $1.1 \mathrm{mmol} / \mathrm{L}(20 \mathrm{mg} / \mathrm{dL})$ of fasting blood glucose over 5.5 $\mathrm{mmol} / \mathrm{L}(100 \mathrm{mg} / \mathrm{dL})$ (19) (Table 3). The dose should not be adjusted more frequently than 3-day intervals. Preprandial supplemental rapid-acting insulin is often needed. However, many patients with type 2 diabetes require only 1 daily injection of insulin glargine without the addition of preprandial insulin. Of note, although insulin glargine can last up to 24 hours, a waning effect can be seen as early as 15 hours (9), and some patients require 2 doses of insulin glargine in a 24-hour period. However, there is no evidence that this regimen has any advantage over conventional NPH insulin. The preprandial insulin dose should be prescribed according to individual sensitivities and the amount of carbohydrates that are ingested. In general, a dose of 5 to $10 \mathrm{U}$ of short- or rapid-acting insulin is initially prescribed and further adjustments are made to the preprandial insulin dose on the basis of the individual's response.

Another approach is to calculate the initial preprandial insulin dose according to an estimate of the patient's insulin requirements. The total insulin requirement for a patient with type 2 diabetes is estimated to be $0.6 \mathrm{U} / \mathrm{kg}$ (36, 37). Approximately half of the total dose will be basal longacting or intermediate-acting insulin, and one sixth of the total dose $(0.1 \mathrm{U} / \mathrm{kg}$ per meal) will be rapid-acting insulin administered before meals. To improve flexibility, the patient may learn how to adjust for changes in daily intake of dietary carbohydrates. An "insulin-to-carbohydrate" ratio may be calculated to estimate the amount of insulin necessary to cover ingested carbohydrates. This is accomplished by dividing the total preprandial daily insulin dose (in units) by the dietary carbohydrate intake (in grams). Thus, if the patient modifies the composition of carbohydrates at any specific meal, he or she can readjust the preprandial insulin dose to accommodate the carbohydrate load. A supplemental insulin dose ("correction factor") may be added to correct for ambient blood glucose levels before meals. This supplemental dose is calculated by dividing 1500 if regular human insulin is used or 1800 (or 1700 , according to some published literature) $(42,43)$ if rapid-acting insulin analogue is used by the total insulin requirement. This provides an estimate of the patient's sensitivity to insulin (that is, the expected decrease in blood glucose level [in $\mathrm{mg} / \mathrm{dL}$ ] in response to $1 \mathrm{U}$ of insulin). The correction dose of supplemental insulin may be added to the meal-determined insulin requirements to calculate the total preprandial insulin dose that is needed. These preliminary estimates are then adjusted on the basis of the individual's response to therapy. However, these calculations are subject to large interindividual variability, and as such, they should be regarded as first approximations.

Premixed insulins may also be used to achieve control. These preparations are more convenient and less prone to errors in dosing but limit flexibility in diet and lifestyle. The premixed insulin analogues can be preferable to premixed human insulin preparations because they can be taken within 15 minutes of a meal and have better postprandial coverage (44).

Currently, there is no strong rationale to favor glargine, NPH insulin, insulin detemir, or fixed-ratio insulin as the preferred agent for initiating insulin therapy. In 1 study, adding once-daily glargine to sulfonylurea and metformin treatment was more effective than withdrawing oral antiglycemic drugs and initiating twice-daily injections of human premixed 70/30 insulin (45). In this trial, glargine was adjusted according to fasting blood glucose levels by 
using the algorithm summarized in Table 3. The design of this study, notably the withdrawal of oral antiglycemic drugs in the insulin 70/30 arm of the study, does not allow for direct comparison between the insulin glargine regimen and the twice-daily premixed human insulin regimen. In another study of 233 insulin-naive diabetic patients receiving metformin alone or in combination with other oral antiglycemic agents, initiating insulin therapy with twicedaily biphasic insulin aspart 70/30 was more effective in achieving hemoglobin $A_{1 c}$ targets than once-daily glargine (41). In this study, insulin therapy was initiated at a total daily dose of 10 to $12 \mathrm{U}$ administered within 15 minutes before breakfast and supper (evening meal). The presupper dose was titrated on the basis of fasting blood glucose levels and the prebreakfast dose was titrated on the basis of presupper levels to achieve a target blood glucose value of 4.4 to $6.05 \mathrm{mmol} / \mathrm{L}$ ( 80 to $110 \mathrm{mg} / \mathrm{dL}$ ). Dose titration was based on plasma glucose levels from the preceding 3 days (Table 4). If 2 of the 3 readings for a specified period (prebreakfast or presupper) were not within target, the insulin dose was adjusted on the basis of the lower of the 2 plasma glucose readings unless hypoglycemia was occurring (41). In a similar study, insulin therapy was initiated with either twice-daily insulin lispro mix $75 / 25$ or once-daily glargine, both taken concomitantly with metformin (46). Reduction in hemoglobin $\mathrm{A}_{1 \mathrm{c}}$ level was greater in the lispro mix group, and more patients reached the target hemoglobin $A_{1 c}$ level of less than $7 \%$ in 16 weeks when treated with the lispro mix than with glargine ( $41 \%$ vs. $22 \%$; $P<$ 0.001) (46).

Currently, the decision of whether to start the patient on glargine administered once per day, intermediate-acting insulin administered twice per day, or mixed-insulin preparation must be individualized.

\section{Profile 2: Fasting Hyperglycemia and Daytime Euglycemia}

Patients who have this blood glucose profile tend to be middle-aged, overweight, or possibly active individuals who often consume most of their daily calories from supper through snacks until bedtime (Table 2). Alternatively, some individuals may eat many small meals during the day (a "grazing" pattern of eating) and be physically active. If the individual is already taking oral antidiabetic agents, the clinical efficacy of the oral agent, especially of the insulin secretagogues, may not last for 24 hours. The insulin of choice in these patients is either an intermediate-acting insulin preparation, such as NPH or insulin detemir given at bedtime, or short-acting insulin given before supper. The choice of insulin is determined by the level of blood glucose at bedtime. If the bedtime blood glucose level exceeds $7.7 \mathrm{mmol} / \mathrm{L}(140 \mathrm{mg} / \mathrm{dL})$, then the patient can reduce postdinner snacking (a preferred option, especially if the goal is modest weight loss) or take short-acting insulin before supper. Some patients may benefit from mixing regular human insulin with rapid-acting insulin. That combination may be taken within 15 minutes of supper and provides enough insulin to cover postdinner snacking. If the individual's bedtime blood glucose level is not elevated, then intermediate-acting insulin at bedtime would be preferred. In these persons, checking midnight blood glucose levels periodically (that is, once per week initially) would ensure that the individual is not experiencing nighttime hypoglycemia that may be aggravating the elevations in fasting blood glucose levels.

\section{Profile 3: Daytime Hyperglycemia and Fasting Euglycemia}

This profile with predominantly postprandial hyperglycemia can occur in patients with early-stage type 2 diabetes or in those with advanced disease who are already taking more than 1 oral antiglycemic drug. It is also a common profile in many women with gestational diabetes. In addition, several other patient groups have this blood glucose profile (Table 2), including patients with end-stage liver disease or end-stage kidney disease and those receiving high-dose glucocorticoid therapy once daily in the morning for immunosuppression or for treatment of chronic obstructive pulmonary disease.

If these patients are willing to limit the amount of carbohydrates consumed per meal and maintain consistency from day to day, they may do well on a single injection of intermediate-acting insulin administered in the morning. However, many patients, especially those receiv-

Table 4. Titration Schedule for Premixed Insulins*

\begin{tabular}{|c|c|c|c|}
\hline $\begin{array}{l}\text { Fasting Blood Glucose } \\
\text { Levels for } 3 \text { Consecutive } \\
\text { Days, } \mathrm{mmol} / \mathrm{L}(\mathrm{mg} / \mathrm{dL})\end{array}$ & $\begin{array}{l}\text { Adjustment of } \\
\text { Presupper } \\
\text { Insulin Doset }\end{array}$ & $\begin{array}{l}\text { Presupper Glucose } \\
\text { Levels for } 3 \text { Consecutive } \\
\text { Days, } \mathrm{mmol} / \mathrm{L}(\mathrm{mg} / \mathrm{dL})\end{array}$ & $\begin{array}{l}\text { Adjustment of } \\
\text { Prebreakfast } \\
\text { Insulin Dose, } U\end{array}$ \\
\hline$>9.90(>180)$ & 6 & $>9.90(>180)$ & 6 \\
\hline 7.76 to 9.90 (141 to 180$)$ & 4 & 7.76 to 9.90 (141 to 180$)$ & 4 \\
\hline 6.11 to 7.70 (111 to 140$)$ & 2 & 6.11 to 7.70 (111 to 140$)$ & 2 \\
\hline 4.40 to 6.05 (80 to 110$)$ & Maintain dose & 4.40 to 6.05 (80 to 110$)$ & Maintain dose \\
\hline 3.30 to 4.35 (60 to 79$)$ & -2 & 3.30 to 4.35 (60 to 79$)$ & -2 \\
\hline$<3.30(<60) \ddagger$ & -4 & $<3.30(<60) \ddagger$ & -4 \\
\hline
\end{tabular}

* Start with total daily dose of 10 to 12 units. The efficacy and safety of this insulin regimen have been shown in clinical trials. Adapted from reference 41.

†Tested with biphasic aspart $70 / 30$ insulin.

¥If any single blood glucose measurement is in this range, make the appropriate reduction in insulin dose ( $\geq 4 \mathrm{U}$ ). 
ing glucocorticoid therapy, require 1 or more preprandial injections of short-acting insulin to control blood glucose levels. Rapid-acting analogues are not approved for use during pregnancy, although retrospective reviews of medical records of diabetic women treated with insulin lispro (Humalog, Eli Lilly) before conception and throughout pregnancy did not find any adverse maternal or fetal outcomes (47). In a small study comparing the efficacy of insulin aspart with that of regular human insulin in women with gestational diabetes, insulin aspart was associated with effective postprandial glycemic control (48). The safety and efficacy of insulin analogues during pregnancy were recently reviewed (49). There are no randomized studies showing the safety and efficacy of insulin analogues during pregnancy.

As inhaled insulin becomes available, persons who predominantly have postprandial hyperglycemia and do not have any clinically significant comorbid conditions may benefit from the convenience of this mode of therapy.

\section{Combination Therapy for InsULIN AND OraL AGENTS}

Insulin therapy is often combined with oral agents in patients with type 2 diabetes or in those who have type 1 diabetes and insulin resistance $(3,28,35,50)$ (that is, those requiring $>40 \mathrm{U}$ of insulin per day). In patients with early secondary failure of sulfonylurea agents, the addition of bedtime insulin may be sufficient to achieve the glycemic goal. This regimen of bedtime insulin and daytime sulfonylurea has been successfully implemented in many patients with type 2 diabetes (3). The concomitant use of metformin or a thiazolidenedione agent in patients with insulin resistance may be beneficial. The advantage of metformin is that it limits the weight gain commonly observed with initiation of insulin therapy. The continuation of metformin or thiazolidenedione therapy in insulin-treated patients may allow simplification of insulin administration schedules $(3,28,35,50)$. The addition of an $\alpha$-glucosidase inhibitor, such as acarbose or miglitol, with 1 or more meals per day may also allow reduction of the number of daily insulin injections (28). For a more comprehensive review of available oral antidiabetic agents, the reader is referred to previously published reviews on the topic (3, $28,35,50)$.

\section{Monitoring Glycemic Control}

Recommendations for monitoring glycemic control in insulin-treated patients include daily self-monitoring of blood glucose levels and periodic measurement of glycated hemoglobin. Self-monitoring of blood glucose levels provides a profile of daily glycemic fluctuation, reflecting effects of meals, physical activity, and action of the specific components of the insulin regimen. The glycated hemoglo- bin assesses the long-term adequacy of the treatment plan in meeting glycemic goals (51).

At the initiation of insulin therapy, patients are generally asked to monitor blood glucose levels 4 times daily, including before meals and at bedtime. Once satisfactory glycemic control has been established, patients using intensive multiple-injection regimens or insulin pumps must continue to monitor blood glucose levels at least 3 times daily. Patients treated with simpler regimens, such as 1 or 2 daily injections of intermediate- or long-acting insulin, may need to test only once or twice per day (51). In the latter case, rotating premeal and bedtime self-monitoring blood glucose tests over a period of several weeks should provide sufficient data at each essential test point to produce an adequate overall profile of glycemic control. The self-monitoring schedules should be adjusted to specific patient needs and may require intensification during intercurrent illness, during pregnancy, or when there are changes in daily routines. Additional tests may be necessary, for example, at 2:00 a.m. or 1 to 2 hours after a meal to assess overnight hypoglycemia and postprandial glycemic excursions, respectively. Although the importance of postprandial self-monitoring of blood glucose has been shown for pregnant women, the routine use of this measurement is controversial in insulin-treated patients who are not pregnant $(32,52,53)$.

The glycated hemoglobin (also known as glycohemoglobin, glycosylated hemoglobin, hemoglobin $\mathrm{A}_{1 \mathrm{c}}$ ) reflects nonenzymatic glucose binding to hemoglobin in circulating erythrocytes. Because erythrocyte turnover is 90 to 120 days, the glycated hemoglobin measurement represents the mean glycemic control over the preceding 2 to 3 months. Conditions that alter erythrocyte turnover, such as severe anemia, hemolysis, or hemoglobinopathy, will result in glycated hemoglobin measurements that do not correlate with the results of self-monitoring tests (54). Lack of correlation should trigger investigation for such underlying conditions and for inaccurate measurement or reporting of self-monitored blood glucose. Based on results of the Diabetes Complications and Control Trial, the goal for nonpregnant, insulin-treated adults is a glycated hemoglobin level of $7.0 \%$ or less that is as close to the normal range as possible without subjecting the patient to repetitive severe hypoglycemia (54). Glycated hemoglobin is measured every 3 months after initiation or alteration of treatment for diabetes until targeted goals have been achieved. Once glycemic control is stabilized in the desired range, measurements may be limited to 6-month intervals (51).

\section{CONCLUSIONS}

The spectrum of individual blood glucose profiles is wide. For practical purposes, and at the risk of oversimplification, these blood glucose profiles can be divided into 3 general patterns (Table 2). Prescribing insulin is a dynamic process, and the patient should be prepared to adjust the 
regimen as additional information about blood glucose changes becomes available. Diabetes educators and nutritionists play a vital role in the management of these patients. In addition to proficiency in counting carbohydrates and diligence in self-monitoring of blood glucose, patients with diabetes should be able to continuously evaluate their individual blood glucose responses to foods they consume and to physical activity. In general, insulin analogues enhance flexibility and convenience for insulin-treated patients, and recent studies have shown that flexible intensive insulin management can be cost-effective and can be associated with an improvement in quality of life (13). It is now easier to achieve the American Diabetes Association's recommended goal of a hemoglobin $A_{1 c}$ level of less than $7 \%$. However, the new insulin preparations are more expensive than conventional insulin preparations and the cost may be a limiting factor for some patients.

From St. Louis University School of Medicine, St. Louis, Missouri.

Acknowledgments: The authors thank the nursing and pharmacy staff and the residents and students training in the Division of Endocrinology, St. Louis University Hospital, for their valuable discussions over many years of caring for people with diabetes.

\section{Grant Support: None.}

Potential Financial Conflicts of Interest: Consultancies: A.D. Mooradian (Aventis, Novo Nordisk, Eli Lilly Inc.); Honoraria: A.D. Mooradian (Eli Lilly Inc., Aventis, Novo Nordisk); Grants received: A.D. Mooradian (Novo Nordisk, Eli Lilly Inc., Aventis).

Requests for Single Reprints: Arshag D. Mooradian, MD, Department of Internal Medicine, University of Florida, 653-1 West 8th Street, 4th Floor, LRC, Jacksonville, FL 32209; e-mail, arshag.mooradian@jax.uf .edu.

Current author addresses are available at www.annals.org.

\section{References}

1. The effect of intensive treatment of diabetes on the development and progression of long-term complications in insulin-dependent diabetes mellitus. The Diabetes Control and Complications Trial Research Group. N Engl J Med. 1993; 329:977-86. [PMID: 8366922]

2. Oiknine R, Bernbaum M, Mooradian AD. A critical appraisal of the role of insulin analogues in the management of diabetes mellitus. Drugs. 2005;65:32540. [PMID: 15669878]

3. Riddle MC. Glycemic management of type 2 diabetes: an emerging strategy with oral agents, insulins, and combinations. Endocrinol Metab Clin North Am. 2005;34:77-98. [PMID: 15752923]

4. Wang F, Carabino JM, Vergara CM. Insulin glargine: a systematic review of a long-acting insulin analogue. Clin Ther. 2003;25:1541-77. [PMID: 12860485] 5. Gerich JE. Novel insulins: expanding options in diabetes management. Am J Med. 2002;113:308-16. [PMID: 12361817]

6. Vajo Z, Fawcett J, Duckworth WC. Recombinant DNA technology in the treatment of diabetes: insulin analogs. Endocr Rev. 2001;22:706-17. [PMID: 11588149]

7. Dunn CJ, Plosker GL, Keating GM, McKeage K, Scott LJ. Insulin glargine: an updated review of its use in the management of diabetes mellitus. Drugs. 2003;63:1743-78. [PMID: 12904090]

8. Chapman TM, Noble S, Goa KL. Insulin aspart: a review of its use in the management of type 1 and 2 diabetes mellitus. Drugs. 2002;62:1945-81. [PMID: 12215068]

9. McKeage K, Goa KL. Insulin glargine: a review of its therapeutic use as a long-acting agent for the management of type 1 and 2 diabetes mellitus. Drugs. 2001;61:1599-624. [PMID: 11577797]

10. Howey DC, Bowsher RR, Brunelle RL, Woodworth JR. [Lys(B28), Pro(B29)]-human insulin. A rapidly absorbed analogue of human insulin. Diabetes. 1994;43:396-402. [PMID: 8314011]

11. Simpson KL, Spencer CM. Insulin aspart. Drugs. 1999;57:759-67. [PMID: 10353301]

12. Barlocco D. Insulin glulisine. Aventis Pharma. Curr Opin Investig Drugs. 2003;4:1240-4. [PMID: 14649217]

13. Ristic S, Bates PC. Effects of rapid-acting insulin analogs on overall glycemic control in type 1 and type 2 diabetes mellitus. Diabetes Technol Ther. 2003;5: 57-66. [PMID: 12725708]

14. Rami B, Schober E. Postprandial glycaemia after regular and lispro insulin in children and adolescents with diabetes. Eur J Pediatr. 1997;156:838-40. [PMID: 9392394]

15. Rutledge KS, Chase HP, Klingensmith GJ, Walravens PA, Slover RH, Garg SK. Effectiveness of postprandial Humalog in toddlers with diabetes. Pediatrics. 1997;100:968-72. [PMID: 9374566]

16. Gerich JE. Insulin glargine: long-acting basal insulin analog for improved metabolic control. Curr Med Res Opin. 2004;20:31-7. [PMID: 14741069]

17. Hamann A, Matthaei S, Rosak C, Silvestre L. A randomized clinical trial comparing breakfast, dinner, or bedtime administration of insulin glargine in patients with type 1 diabetes. Diabetes Care. 2003;26:1738-44. [PMID: 12766103]

18. Yki-Järvinen H, Dressler A, Ziemen M. Less nocturnal hypoglycemia and better post-dinner glucose control with bedtime insulin glargine compared with bedtime NPH insulin during insulin combination therapy in type 2 diabetes. HOE 901/3002 Study Group. Diabetes Care. 2000;23:1130-6. [PMID: 10937510]

19. Riddle MC, Rosenstock J, Gerich J. The treat-to-target trial: randomized addition of glargine or human NPH insulin to oral therapy of type 2 diabetic patients. Diabetes Care. 2003;26:3080-6. [PMID: 14578243]

20. Heinemann L, Sinha K, Weyer C, Loftager M, Hirschberger S, Heise T. Time-action profile of the soluble, fatty acid acylated, long-acting insulin analogue NN304. Diabet Med. 1999;16:332-8. [PMID: 10220208]

21. Markussen J, Havelund S, Kurtzhals P, Andersen AS, Halstrøm J, Hasselager E, et al. Soluble, fatty acid acylated insulins bind to albumin and show protracted action in pigs. Diabetologia. 1996;39:281-8. [PMID: 8721773]

22. Kurtzhals P, Havelund S, Jonassen I, Kiehr B, Ribel U, Markussen J. Albumin binding and time action of acylated insulins in various species. J Pharm Sci. 1996;85:304-8. [PMID: 8699334]

23. Plank J, Bodenlenz M, Sinner F, Magnes C, Görzer E, Regittnig W, et al. A double-blind, randomized, dose-response study investigating the pharmacodynamic and pharmacokinetic properties of the long-acting insulin analog detemir. Diabetes Care. 2005;28:1107-12. [PMID: 15855574]

24. Heise T, Weyer C, Serwas A, Heinrichs S, Osinga J, Roach P, et al. Time-action profiles of novel premixed preparations of insulin lispro and NPL insulin. Diabetes Care. 1998;21:800-3. [PMID: 9589244]

25. Bott U, Ebrahim S, Hirschberger S, Skovlund SE. Effect of the rapid-acting insulin analogue insulin aspart on quality of life and treatment satisfaction in patients with Type 1 diabetes. Diabet Med. 2003;20:626-34. [PMID: 12873289]

26. Buse JB, Polonsky KS, Burant CF. Type 2 diabetes mellitus. In: Larsen PR, Kronenberg HM, Melmed S, Polonksy KS, eds. Williams Textbook of Endocrinology. 10th ed. Philadelphia: Elsevier Science; 2003:1441-2.

27. Inzucchi SE. Oral antihyperglycemic therapy for type 2 diabetes: scientific review. JAMA. 2002;287:360-72. [PMID: 11790216]

28. Chehade JM, Mooradian AD. A rational approach to drug therapy of type 2 diabetes mellitus. Drugs. 2000;60:95-113. [PMID: 10929931]

29. Maggs DG, Buchanan TA, Burant CF, Cline G, Gumbiner B, Hsueh WA, et al. Metabolic effects of troglitazone monotherapy in type 2 diabetes mellitus. A randomized, double-blind, placebo-controlled trial. Ann Intern Med. 1998;128: 176-85. [PMID: 9454525]

30. DeFronzo RA, Goodman AM. Efficacy of metformin in patients with noninsulin-dependent diabetes mellitus. The Multicenter Metformin Study Group. N Engl J Med. 1995;333:541-9. [PMID: 7623902]

31. Mooradian AD, Thurman JE. Drug therapy of postprandial hyperglycaemia. 
Drugs. 1999;57:19-29. [PMID: 9951949]

32. American Diabetes Association. Postprandial blood glucose. Diabetes Care. 2001;24:775-8. [PMID: 11315848]

33. Riddle MC, Drucker DJ. Emerging therapies mimicking the effects of amylin and glucagon-like peptide 1. Diabetes Care. 2006;29:435-49. [PMID: $16443905]$

34. Weyer C, Bogardus C, Mott DM, Pratley RE. The natural history of insulin secretory dysfunction and insulin resistance in the pathogenesis of type 2 diabetes mellitus. J Clin Invest. 1999;104:787-94. [PMID: 10491414]

35. DeFronzo RA. Pharmacologic therapy for type 2 diabetes mellitus. Ann Intern Med. 1999;131:281-303. [PMID: 10454950]

36. Clement S, Braithwaite SS, Magee MF, Ahmann A, Smith EP, Schafer RG, et al. Management of diabetes and hyperglycemia in hospitals. Diabetes Care. 2004;27:553-91. [PMID: 14747243]

37. Trence DL, Kelly JL, Hirsch IB. The rationale and management of hyperglycemia for in-patients with cardiovascular disease: time for change. J Clin Endocrinol Metab. 2003;88:2430-7. [PMID: 12788838]

38. Retnakaran R, Hochman J, DeVries JH, Hanaire-Broutin H, Heine RJ, Melki V, et al. Continuous subcutaneous insulin infusion versus multiple daily injections: the impact of baseline A1c. Diabetes Care. 2004;27:2590-6. [PMID: 15504991]

39. Pickup J, Mattock M, Kerry S. Glycaemic control with continuous subcutaneous insulin infusion compared with intensive insulin injections in patients with type 1 diabetes: meta-analysis of randomised controlled trials. BMJ. 2002; 324:705. [PMID: 11909787]

40. Oiknine R, Mooradian AD. Drug therapy of diabetes in the elderly. Biomed Pharmacother. 2003;57:231-9. [PMID: 12888259]

41. Raskin P, Allen E, Hollander P, Lewin A, Gabbay RA, Hu P, et al. Initiating insulin therapy in type 2 diabetes: a comparison of biphasic and basal insulin analogs. Diabetes Care. 2005;28:260-5. [PMID: 15677776]

42. UKHealth Care. UK insulin protocols. Accessed at www.mc.uky.edu/ pharmacy/dic/criteria/UKinsulinprotocols.pdf on 30 May 2006.

43. Making bolus insulin changes. Accessed at www.bddiabetes.com/us/ download/insulin_adjustment_workbook_section3.pdf on 30 May 2006.

44. Roach P, Yue L, Arora V. Improved postprandial glycemic control during treatment with Humalog Mix25, a novel protamine-based insulin lispro formulation. Humalog Mix25 Study Group. Diabetes Care. 1999;22:1258-61. [PMID: 10480767]

45. Janka HU, Plewe G, Riddle MC, Kliebe-Frisch C, Schweitzer MA, YkiJärvinen $\mathrm{H}$. Comparison of basal insulin added to oral agents versus twice-daily premixed insulin as initial insulin therapy for type 2 diabetes. Diabetes Care. 2005;28:254-9. [PMID: 15677775]

46. Malone JK, Kerr LF, Campaigne BN, Sachson RA, Holcombe JH. Combined therapy with insulin lispro Mix 75/25 plus metformin or insulin glargine plus metformin: a 16-week, randomized, open-label, crossover study in patients with type 2 diabetes beginning insulin therapy. Clin Ther. 2004;26:2034-44. [PMID: 15823767]

47. Garg SK, Frias JP, Anil S, Gottlieb PA, MacKenzie T, Jackson WE. Insulin lispro therapy in pregnancies complicated by type 1 diabetes: glycemic control and maternal and fetal outcomes. Endocr Pract. 2003;9:187-93. [PMID: 12917059]

48. Pettitt DJ, Ospina P, Kolaczynski JW, Jovanovic L. Comparison of an insulin analog, insulin aspart, and regular human insulin with no insulin in gestational diabetes mellitus. Diabetes Care. 2003;26:183-6. [PMID: 12502678] 49. Gamson K, Chia S, Jovanovic L. The safety and efficacy of insulin analogs in pregnancy. J Matern Fetal Neonatal Med. 2004;15:26-34. [PMID: 15101608] 50. Edelman SV, Morello CM. Strategies for insulin therapy in type 2 diabetes. South Med J. 2005;98:363-71. [PMID: 15813164]

51. American Diabetes Association. Standards of Medical Care in Diabetes2006. Diabetes Care. 2006;29 Suppl 1:S4-S42. [PMID: 16373931]

52. Metzger BE, Coustan DR. Summary and recommendations of the Fourth International Workshop-Conference on Gestational Diabetes Mellitus. The Organizing Committee. Diabetes Care. 1998;21 Suppl 2:B161-7. [PMID: 9704245]

53. American Diabetes Association. Gestational diabetes mellitus. Diabetes Care. 2004; 27 Suppl. 1:S88-S90. [PMID: 14693936]

54. Sacks DB, Bruns DE, Goldstein DE, Maclaren NK, McDonald JM, Parrott $\mathrm{M}$. Guidelines and recommendations for laboratory analysis in the diagnosis and management of diabetes mellitus. Clin Chem. 2002;48:436-72. [PMID: 11861436 


\section{Annals of Internal Medicine}

Current Author Addresses: Dr. Mooradian: Department of Medicine, University of Florida, 653-1 West 8th Street, 4th Floor, LRC, Jacksonville, FL 32209.
Drs. Bernbaum and Albert: Division of Endocrinology, Saint Louis University Medical School, 1402 South Grand Boulevard, St. Louis, MO 63104. 